\title{
A sustentabilidade dos solos a partir das percepções de estudantes de uma escola do campo
}

\author{
The soil sustainability about field school student's perceptions
}

\author{
Patrícia Daiane Loebens Diel Wiethölter ${ }^{1}$; Maria Rosa Chitolina Schetinger ${ }^{2}$
}

1 Mestra em Educação em Ciências: Química da Vida e Saúde, Universidade Federal de Santa Maria, Santa Maria, Rio Grande do Sul, Brasil - patydiel@bol.com.br/ orcid: 0000-0001-6162-7083

2 Doutora em Bioquímica, Universidade Federal de Santa Maria, Santa Maria, Rio Grande do Sul, Brasil mariachitolina@gmail.com/ orcid: 0000-0002-5240-8935

\section{Recebido em 20/12/2017. Publicado em Dezembro/2019}

\section{Palavras-chave: \\ Educação. \\ Sustentabilidade. \\ Sustentabilidade dos solos. Escola do campo.}

\section{Keywords:}

Education.

Sustainability. Soil sustainability. Field school.
RESUMO: A sustentabilidade dos solos é um tema de grande importância para o equilíbrio e a continuidade da produção de alimentos. Ao pensar em produção de alimentos, referimo-nos aos agricultores familiares e seus filhos, estudantes inseridos neste meio ou, mais propriamente, na educação do campo. O presente artigo trata de análise das percepções de estudantes de $6^{\circ}$ ano de ensino fundamental de uma escola do campo do município de Tuparendi, estado do Rio Grande do Sul, acerca de sustentabilidade dos solos. Durante a pesquisa, realiza-se um comparativo entre as percepções prévias e pós prática contextualizada de sala de aula, que trata de atividades que permeiam as práticas corretas de manejo e conservação do solo. Busca-se, neste sentido, identificar e analisar estas percepções e se as mesmas possuem interfaces com as referências do pensar para a sustentabilidade, utilizandoas para ressignificar o conceito de sustentabilidade dos solos. Após atividade contextualizada, observa-se que os estudantes enriquecem suas percepções, e que a clareza nas respostas quanto ao manejo correto de solo é favorecida. Também destaca-se que a escola, enquanto do campo, e seus atores (sejam professores, estudantes, pais e demais envolvidos), conscientizem-se de seu papel e suas ações frente ao meio. Com uma educação voltada à realidade e ao contexto, aliada ao comprometimento à continuidade das espécies e elementos primordiais à vida, promove-se a reflexão, seguida de sensibilização, com vistas à prática da sustentabilidade.

ABSTRACT: The soil sustainability is a great importance subject for the balance and continuity of food production. When thinking about food production, we refer to family farmers and their children, students inserted in this environment or, more properly, on field education. This article analyze of $6^{\text {th }}$ grade students perceptions from Tuparendi city field school, Rio Grande do Sul state, about soil sustainability. During the research, a comparison made between previous perceptions and postcontextual classroom practice, which deals with activities that permeate the correct practices of soil management and conservation. In this sense, we seek identify and analyze these perceptions and if the same have interfaces with references of think the sustainability, using to resignify the concept of soil sustainability. After contextualized activity, observed that students enrich their perceptions and the clarity is favored in the answers about soil management. Also stands out that school, while field, and their actors (be teachers, students, parents and others involved), aware of their role and actions on the environment. With an targeted education on reality and context, allied with commitment to the continuity of species and primordial elements to life, promoted the reflection, followed by awareness, with a view to the practice of 
sustainability.

\section{INTRODUÇÃO}

A sustentabilidade, cada vez mais ganha reconhecimento, uma vez que trata dos assuntos relacionados ao meio ambiente e preservação da espécie. Neste sentido, Gliessman (2000) defende que seu significado é diferente para as pessoas, sendo que há concordância quando se fala que a mesma tem uma base ecológica.

No sentido mais amplo, a sustentabilidade é uma versão do conceito de produção sustentável - a condição de ser capaz de perpetuamente colher biomassa de um sistema, porque sua capacidade de se renovar ou ser renovado não é comprometida (GLIESSMAN, 2000, p. 52).

Assim, o estudo de práticas conservacionistas de solos contempla a visão da sustentabilidade que Gliessman (2000, p. 209) defende, pois “o solo é um componente complexo, vivo, dinâmico e em transformação do agroecossistema. Está sujeito a alterações e pode ser degradado ou manejado sabiamente."

Para a autora Ana Primavesi (2014), a reflexão sobre a importância do solo e do meio ambiente como um todo perpassa conceitos de sustentabilidade, ao relacionar a preocupação com os recursos naturais e a continuidade dos mesmos, no que a mesma afirma:

Parece que a maioria das pessoas esqueceu que cidade alguma, seja grande, esplêndida e rica, pode garantir a vida. A vida vem do campo, da terra, do solo que produz nossos alimentos. E mesmo o mais rico gênio em informática que vive em mundos virtuais não escapa do fato de necessitar manter a sua vida por meio de alimentos produzidos em solos reais, regados pela chuva e pela água dos rios (PRIMAVESI, 2014, p. 15).

Nesse sentido, o presente artigo tem como finalidade analisar as percepções de estudantes de $6^{\circ}$ ano do ensino fundamental, de uma escola do campo do município de Tuparendi - RS, a respeito de sustentabilidade dos solos. A partir de questionário e entrevista, busca-se analisar as concepções prévias e pós práticas de sala de aula, sobre o tema relacionado.

Ao analisar as percepções dos estudantes sobre a sustentabilidade dos solos, busca-se fazer um comparativo com a bibliografia sobre sustentabilidade (o conceito em si) e também no que tange o desenvolvimento sustentável dos solos. Cabe destacar que as concepções prévias e as construídas após prática contextualizada de sala de aula são avaliadas a fim de diagnosticar se estas possuem interface com as referências do pensar o termo sustentabilidade. A partir destas coletas e análises, procura-se ressignificar o conceito "sustentabilidade de solos". 
Os sujeitos da pesquisa, estudantes de ensino fundamental, participaram de um estudo sobre as contribuições de uma sequência didática contextualizada a respeito de sustentabilidade dos solos. A metodologia de pesquisa-ação foi utilizada para a realização do estudo, sendo que os estudantes, na sua maioria, residem no meio rural e obtém da agricultura, o sustento da família.

Segundo Thiollent (1985) e Gil (2002) a pesquisa-ação refere-se à imersão do pesquisador no ambiente de pesquisa e se caracteriza pela intervenção contínua do mesmo no ambiente objeto de estudo. Pode-se dizer que a pesquisadora, por fazer parte do contexto em questão e por intervir diretamente com os estudantes e suas famílias, através da assistência técnica e extensão rural estadual, a fim de encontrar e propor melhorias com as diferentes partes envolvidas, caracterizaram este modelo de pesquisa.

Os estudantes provêm de famílias de agricultores familiares, onde atividades como produção para autoconsumo, bovinocultura de leite e grãos, são as fontes de renda principais. Cabe destacar aqui que grãos como soja, milho e trigo, juntamente com a bovinocultura de leite, são os principais propulsores da economia da região referenciada no estudo.

Conforme Pires e Baptista (2013), caracteriza-se o agricultor familiar como participante de um grupo social que contribui de forma significativa para a geração de trabalho e economia do país. Continuam, destacando que pensar na agricultura familiar é pensar no campo como espaço de vida e de convivência, espaço de diversidade cultural e natural, cumprindo um importante papel de preservação e conservação dos recursos naturais como a água, o solo e o patrimônio genético que são as sementes agrícolas, ornamentais e florestais. Concluem que pensar na agricultura familiar é pensar em formas plurais de cultivo e de criatórios e em dizer não a monocultivos, sejam eles quais forem.

A escola do campo em que a pesquisa foi realizada é um educandário estadual, com mais de 60 anos de atuação e de acordo com seu Projeto Político Pedagógico (PPP), tem-se uma preocupação quanto às mudanças em âmbito local, regional e globalizado, e a mesma procura formar um "cidadão consciente de seus direitos e deveres, participativo, crítico, comprometido com a realidade em que vive, buscando uma sociedade democrática e solidária" e ainda fundamenta sua educação em valores como "solidariedade, honestidade, responsabilidade, respeito e autonomia" (ESCOLA ESTADUAL DE ENSINO FUNDAMENTAL ANDREA PARISE, 2010). Nesse sentido, deve-se levar em consideração, que a escola é o espaço onde debates sobre a preservação do meio e sustentabilidade devem estar sempre presentes, independente das disciplinas, com foco integrado, incitando metodologias participativas e interdisciplinares. 
Nestes preceitos a pesquisa busca consolidar que a prática relacionada à vivência real do sujeito tem grande importância no processo de ensino-aprendizagem, bem como Freire coloca "Por que não discutir com os alunos a realidade concreta a que se deva associar a disciplina cujo conteúdo se ensina [...]?” (FREIRE, 2011, p. 32).

A contextualização na educação, no que se refere a sustentabilidade e o meio ambiente, é um ponto positivo ao se tratar de educação do campo, pois os estudantes, inseridos no meio em que vivem, aproximam os conhecimentos reais e vivenciais do conhecimento científico. De acordo com a Resolução CNE 01 de 03/04/02, que dispõe sobre as diretrizes operacionais para a educação básica nas escolas do campo, em seu parágrafo único, artigo $2^{\circ}$, coloca que a identidade das escolas do campo são definidas pelo vínculo com as questões da sua realidade, ancorando-se na temporalidade e saberes próprios dos estudantes, na memória coletiva que sinaliza futuros, na rede de ciência e tecnologia disponível na sociedade e nos movimentos sociais em defesa de projetos que associem as soluções exigidas por essas questões à qualidade social da vida coletiva no país (BRASIL, 2002).

Nesse intuito, a população rural ao utilizar o solo como principal elemento para produção de alimentos e consequente geração de renda, deve tratar da sustentabilidade dos solos com real importância, integrando junto ao cultivo suas práticas de conservação. As práticas conservacionistas e de recuperação de solos, segundo Eltz et al. (2007) são procedimentos realizados com o objetivo de manter o solo produtivo e recuperar suas condições de produtividade.

Quanto às práticas de conservação de solo, Eltz et al. (2007) cita algumas, entre elas: adubação mineral, adubação orgânica, adubação verde e plantas de cobertura; sistemas de cultura, calagem; controle de queimadas; cobertura morta, rotação de cultura, consorciação de culturas, cultivos em nível (em contorno), cultivos em faixas, reflorestamento, pastagens, terraceamento, cultivo mínimo, plantio direto. Ao pensar em sustentabilidade, na integração dos solos com o meio ambiente, e este como um todo, é que manifestamos a indagação com o termo sustentabilidade dos solos. O termo sustentabilidade, por conter diversas definições, perpassa por conflitos, porém, aproximamo-nos de um conceito que se preocupa com o ser humano como um todo, na sua integralidade e que o integra no todo. E é essa definição que deve ser compartilhada e vivenciada na educação.

O termo sustentabilidade tem sua trajetória marcada por algumas datas centrais, sendo seu início marcado no ano de 1968, no Clube de Roma, onde estudiosos reúnem-se para discutir assuntos referentes à política, economia, meio ambiente e desenvolvimento 
Ensino, Saúde e Ambiente - V12 (3), pp. 162-180, Dez. 2019

sustentável. Já em 1973, o francês Maurice Strong lança o conceito de Ecodesenvolvimento, que trata de uma política de desenvolvimento alternativo.

Em 1987 surge o termo "Sustentabilidade" apresentado oficialmente na Comissão Mundial sobre Meio Ambiente e Desenvolvimento (CMMAD), da ONU (Organização das Nações Unidas), presidida pela ex-primeira-ministra da Noruega, Gro Harlem Brundtland, e enfatiza que se trata da "[...] capacidade de satisfazer as necessidades do presente sem comprometer a capacidade das gerações futuras de satisfazerem suas próprias necessidades" (CMMAD, 1988, p. 9).

Na Eco 92, ou Cúpula da Terra, realiza-se um acordo em que quase todos os países do mundo se comprometem com a estabilização da concentração dos gases responsáveis pelo efeito estufa. Mais tarde, ganha maior reconhecimento com o Protocolo de Quioto, apresentado em 1997.

Um estudo realizado por Elkington, em meados da década de 90, define os tripés da sustentabilidade, ou a Triple Bottom Line (TBL) e é conhecido pelos 3 P (People, Planet e Profit), no português PPL (Pessoas, Planeta e Lucro), que tem grande influência, ainda nos dias atuais, em todos os setores, principalmente na economia, e que por este motivo é muito criticado.

Atualmente, Boff (2015) define o termo como

[...] toda ação destinada a manter as condições energéticas, informacionais, físicoquímicas que sustentam todos os seres, especialmente a Terra viva, a comunidade de vida, a sociedade e a vida humana, visando sua continuidade e ainda atender as necessidades da geração presente e das futuras, de tal forma que os bens e serviços naturais sejam mantidos e enriquecidos em sua capacidade de regeneração, reprodução e coevolução (BOFF, 2015, p. 107).

Nestes parâmetros, o conceito de sustentabilidade que baliza as linhas gerais do presente trabalho, seguem os preceitos de Boff, ao relacionar a sustentabilidade como linha mestra de sustentação do planeta e das espécies, referindo-se ao solo como integrante essencial para a continuidade da vida.

Diante disso, o presente trabalho pretende verificar e analisar as percepções de estudantes de uma escola do campo acerca de sustentabilidade dos solos, antes e após prática contextualizada de sala de aula, e se há uma inter-relação entre as concepções dos estudantes e as referências do pensar para a sustentabilidade.

\section{METODOLOGIA}


A escola do campo onde a pesquisa foi desenvolvida é a Escola Estadual de Ensino Fundamental Andrea Parise, e se localiza no distrito de Cinquentenário, interior do município de Tuparendi, estado do Rio Grande do Sul. Conta com 122 alunos, provenientes das proximidades da escola, residentes da área rural e caracterizados como agricultores familiares. Possui 14 professores e 8 funcionários em seu quadro de pessoal.

A amostra compreendeu 23 alunos, do $6^{\circ}$ ano de ensino fundamental, sendo que todos concordaram em participar da pesquisa. A pesquisa foi submetida ao Comitê de Ética em Pesquisa e aprovado. Por se tratar de um estudo com crianças menores de idade, os termos de aceite em participar da pesquisa passaram pela ciência dos pais e/ou responsáveis e pelos próprios estudantes.

Para a análise dos dados da pesquisa, foram utilizados dois instrumentos de coleta, que basearam-se em um questionamento aberto estruturado e uma pergunta em forma de entrevista semiestruturada, a fim de coletar as percepções prévias e conhecimento pós prática contextualizada que os estudantes possuem a respeito de sustentabilidade dos solos.

Ao início das atividades aplicou-se o questionário aberto estruturado, entregue em fotocópias individuais, onde os estudantes responderam a pergunta sobre as percepções/entendimento próprio sobre a sustentabilidade dos solos na agricultura. $\mathrm{O}$ mesmo questionário foi entregue ao término das atividades, que compreenderam três meses, aproximadamente. Após foi realizado uma análise comparativa entre as respostas, com o intuito de avaliar a atividade prática contextualizada e as percepções dos alunos frente aos assuntos relacionados.

Já o questionamento em forma de entrevista, aberto e semiestruturado, buscou compreender sobre as percepções dos estudantes acerca da sustentabilidade dos solos. Foi realizado individualmente, onde cada estudante pode expressar suas reais construções de aprendizagem, uma vez que foi realizado ao final da prática de sala de aula.

Os dados coletados na entrevista e questionário foram compilados para o programa Excel. Foram organizados, de acordo com as respostas aproximadas e com mesmo contexto, logo após foram submetidos às categorias de acordo com referenciais da pesquisa.

Todas as atividades realizadas pelos alunos foram identificadas, porém na análise e nos resultados da pesquisa optou-se por não divulgar sua identidade. Desta forma, as respostas serão referenciadas por A - aluno e em seguida, por números, conforme organização do pesquisador (exemplo: A-1, A-2, etc). 
Toda a coleta de dados foi realizada com intuito de analisá-los a priori, e, de acordo com a realização das mesmas, emergiram outras categorias que foram acrescentadas à pesquisa, após leitura e embasamento de referenciais. Para Moraes (2003), a categorização reúne elementos semelhantes, além de nomear e definir as categorias de forma precisa, na medida em que as mesmas vão sendo construídas.

Os dados também foram analisados com auxílio de gráficos e respostas próprias dos estudantes, sendo que ao final, os mesmos ainda foram comparados (questionários iniciais e finais), a fim de verificar as contribuições na construção do conhecimento e nas concepções acerca de sustentabilidade dos solos, e se estas foram importantes para a pesquisa.

\section{RESULTADOS E DISCUSSÃO}

Ao realizar o questionamento inicial e coletar respostas, a fim de analisar as concepções prévias acerca da sustentabilidade dos solos, foram categorizadas por aproximação de conhecimento, com base em referenciais sobre conservação dos solos e sustentabilidade. Do total de 23 questionários, alguns estudantes apresentaram mais de uma resposta, sendo que todas foram contabilizadas e analisadas.

O gráfico 1 apresenta, um comparativo entre as respostas iniciais (prévias) e as finais (pós prática) sobre o entendimento dos mesmos sobre a sustentabilidade dos solos na agricultura.

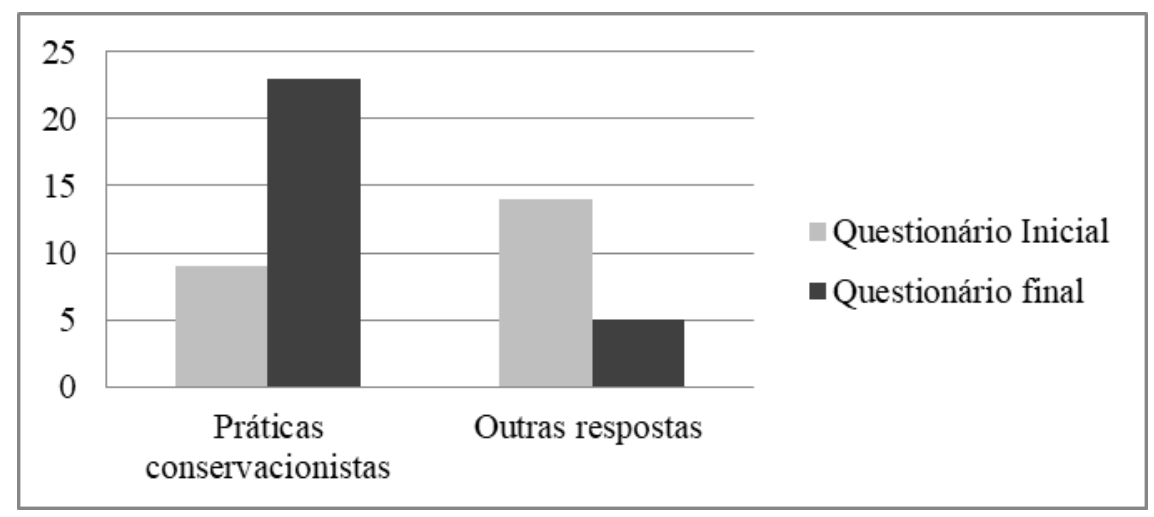

Gráfico 1 - Comparativo entre as respostas iniciais e finais dos estudantes acerca do entendimento sobre sustentabilidade dos solos na agricultura.

Fonte: Autoria própria.

Quando questionados sobre sustentabilidade dos solos na agricultura, no questionário inicial, há uma divergência nas respostas, sendo que os alunos não tem clareza quanto ao conceito de sustentabilidade. Alguns fazem relação com as práticas de cultivo, outros fazem 
Ensino, Saúde e Ambiente - V12 (3), pp. 162-180, Dez. 2019

relação com as práticas corretas de manejo. Todos relacionam com uma agricultura que minimiza os efeitos nocivos da poluição e falta de preservação, porém não se incluem, enquanto sujeitos da mudança, no processo. Assim, sugerem as respostas apresentadas pelos mesmos:

Eu desenhei uma árvore que dará frutos. Os frutos vão cair e apodrecer. Isso vai virar adubo. As folhas também (A-1).

A erosão é muito prejudicial para a terra, pois a água leva todos os nutrientes da terra, se fizermos o plantio direto os nutrientes vão ficar na terra e para a planta (A-7).

Eu desenhei que tem que carpir o inço em vez de passar veneno e proteger as fontes (A-8).

Sustentabilidade é ajudar a natureza e não jogar lixo no chão para não prejudicar a natureza (A-9).

A erosão é prejudicial ao solo mas fazendo o plantio direto a chuva não leva os nutrientes da terra para o rio, pois a palha bloqueia. Assim resultando em um solo melhor para o plantio (A-13).

As raízes seguram o solo, assim, evita o deslizamento. A raiz se alimenta dos nutrientes. Raízes que sustentam o solo (A-21).

A sustentabilidade é a natureza boa ajudando o solo a ficar melhor. Da folha sai a clorofila, planta, a raiz ajuda a puxar o nutriente do solo (A-22).

Cabe salientar que os estudantes têm uma compreensão sobre a importância do solo para a agricultura, mas que o termo sustentabilidade não é muito referenciado nem tampouco que há maior compreensão. Destaca-se que a palavra sustentabilidade vem associada a algo positivo, no caso que pode subentender preservação, conservação, e que isso levaria necessariamente, à preservação e conservação do solo, tornando-o "melhor" no sentido de maior produtividade e menor poluição.

Já no questionário final, as respostas que mais se destacaram:

Plantar coisas para dar cobertura ao solo como aveia, trigo, nabo. Nabo também ajudará a reduzir a compactação do solo gerando um solo melhor (A-1).

Rotação de cultura é muito importante para o solo (A-2).

Essa é a curva de nível corretamente. A curva de nível é importante para não lavar as sementes da lavoura (A-3).

Trator passando ureia para adubar o solo (A-5).

Eu fiz uma plantação de trigo que está sendo irrigada (A-6).

Fazer terraços para não dar erosão no solo e não usar agrotóxicos sem orientação de um especialista (A-14).

Essas são práticas sustentáveis para se usar: plantio em nível, plantio direto, uso correto e com orientação de agrotóxicos, curvas de nível, rotação de culturas (A-15).

Eu desenhei uma plantação de nabo que ajuda a adubar o solo para a próxima plantação (A-16).

Eu fiz o desenho de umas plantas para a sustentabilidade do solo (A-17).

Práticas que devemos fazer para melhorar nossas roças: plantio em nível, palhas para proteger o solo, terra fértil, adubos. Eu acho que sustentabilidade é só ajudar o solo, não prejudicar, e também principalmente a palha que ajuda bastante o solo, e não deixar levar toda a camada fértil do solo (A-21). 
Ensino, Saúde e Ambiente - V12 (3), pp. 162-180, Dez. 2019

Eu acho que sustentabilidade do solo é sustentar os solos fazendo curvas de níveis e deixando uma cobertura para o solo e etc (A-22).

Nas respostas finais, evidencia-se a relação da sustentabilidade com práticas conservacionistas. Os estudantes recordam-se e citam algumas práticas de conservação de solo e fazem relação com o conceito de sustentabilidade, porém poucos evidenciam o termo em si para melhor explicá-lo, a partir de suas percepções.

Como houve um grande número de referências às práticas relacionadas ao manejo correto dos solos, no gráfico 2, realizou-se um comparativo, que compreende as respostas iniciais e finais sobre a estratificação quanto às práticas de conservação de solo lembradas pelos estudantes.

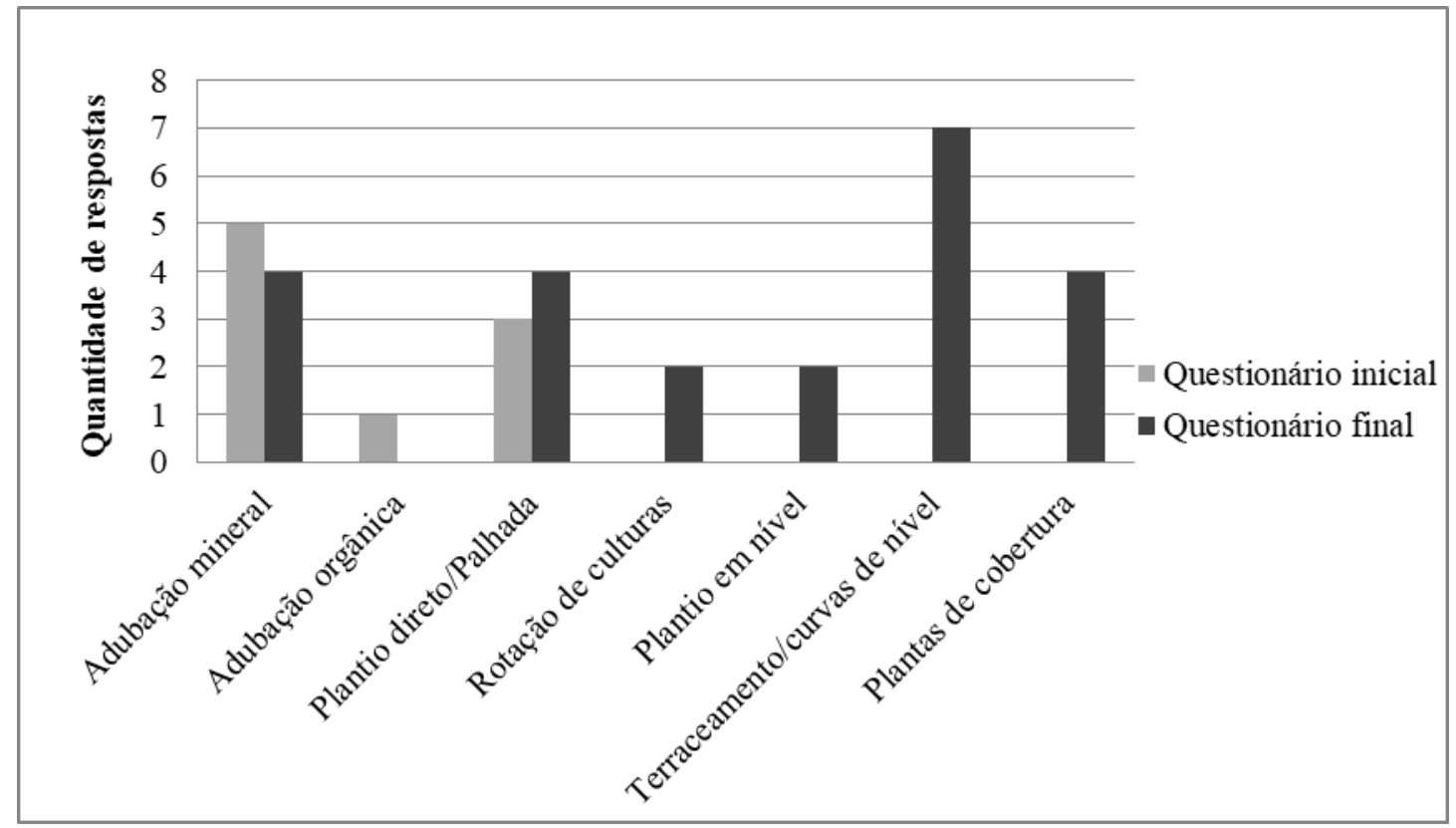

Gráfico 2 - Comparativo entre as respostas iniciais e finais sobre as práticas de conservacionistas de solo relacionadas pelos alunos.

Fonte: Autoria própria.

Estratificando os dados deste questionamento em tipos de práticas conservacionistas de solos que apareceram, cabe destacar o aumento da diversidade dos tipos de práticas levantadas pelos estudantes, após sequência didática contextualizada.

Ao analisar o questionário inicial, a compreensão das práticas conservacionistas ainda é limitada dentro da definição de Eltz et al. (2007), embora façam uma referência abrangente no quesito adubação. Os estudantes possuem um entendimento prévio do que possa promover a sustentabilidade dos solos, mas ainda com pouco embasamento quanto à importância da inserção do sujeito junto à conservação e manejo correto de solos para se tornarem agricultáveis. 
Ensino, Saúde e Ambiente - V12 (3), pp. 162-180, Dez. 2019

Já no questionário final, os estudantes associaram um grande número práticas conservacionistas à sustentabilidade dos solos, demonstrando que a prática contextualizada ampliou os conhecimentos dos mesmos em relação ao conteúdo abordado nas atividades.

Quando se trata de criar condições que permitam o desenvolvimento rural e agrícola sustentável, a Agenda 21 faz referência à conservação e reabilitação da terra, onde cita o problema para com o solo como o mais grave problema ambiental. Reflete que o problema da erosão do solo é particularmente agudo nos países em desenvolvimento, enquanto em todos os países agravam-se os problemas de salinização, encharcamento, poluição do solo e perda da fertilidade do solo. Embora o planejamento do uso das terras e seu zoneamento, associados a um melhor manejo das terras, devam oferecer soluções de longo prazo para o problema da degradação das terras, urge interromper tal degradação e dar início a programas de conservação e reabilitação nas regiões mais seriamente afetadas e mais vulneráveis.

Sendo assim, compreende-se que a sustentabilidade dos solos está diretamente ligada à conservação através da adoção de práticas de manejo correto, sendo que o sujeito deve estar comprometido com o meio, fazendo parte na sua integralidade, e que os reflexos destas ações estarão disponíveis a todos. Pratica o bem a si mesmo, ao meio, e a todos, na sua totalidade e não de forma isolada.

Já na atividade de questionamento aberto semiestruturado através de entrevista, as respostas foram categorizadas de forma emergente, conforme surgiram demandas, onde Moraes e Galiazzi (2016, p. 139) definem esta categoria em que "o pesquisador assume uma atitude fenomenológica de deixar que os fenômenos se manifestem, construindo suas categorias a partir das múltiplas vozes emergentes nos textos que analisa."

Nesta etapa da pesquisa, leva-se em consideração a opinião dos estudantes sobre sustentabilidade, conforme pergunta que segue: “Após estas aulas, na sua opinião, o que podemos dizer que é sustentabilidade dos solos?”.

As respostas obtidas foram classificadas em duas categorias, e aparecem no gráfico 3, as quais se destacaram:

- relação com o ato de sustentar;

- respostas generalizadas, que apresentaram conceitos ligados à preservação, adubação e combate à erosão. 
Ensino, Saúde e Ambiente - V12 (3), pp. 162-180, Dez. 2019

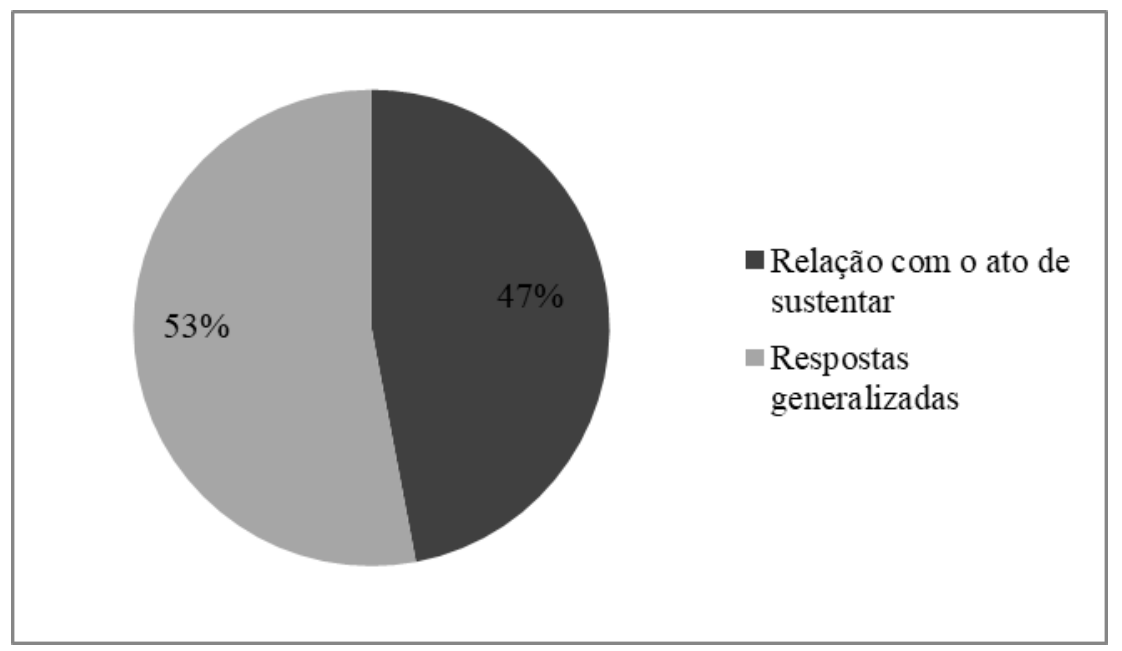

Gráfico 3 - Percepção dos estudantes a respeito de sustentabilidade dos solos após atividades práticas contextualizadas.

Fonte: Autoria própria.

Desta forma, $47 \%$ dos estudantes relacionaram a sustentabilidade dos solos ao ato de sustentar o solo, ou dar sustento para o mesmo se manter. Dentre as respostas, podemos destacar:

Que sustenta o solo [...] assim daí tem o solo fértil, daí tu pode plantar [...] assim vai ter uma plantação mais bonita, mais fértil (A-11).

O que sustenta o solo que a gente sempre tem na roça, não deixar só a terra e o soja sempre, tem que colocar alguma coisa que protege pra quando vir a chuva não lavar toda a camada fértil, porque se não tivesse a proteção a planta não vai ser fértil. E é isso, tem que colocar sempre uma coisa que protege o solo, para ele ser cada vez mais forte, e os adubos também (A-19).

Sustentar o solo, dar mais sustento a ele. Tipo não plantar todo o ano a mesma coisa, planta um ano soja, milho, planta aveia pra ter mais uma camada, pra terra ficar boa (A-20).

Quando sustenta o solo [...] os agricultores às vezes não cuidam o solo. Quando vem a chuva às vezes lava o solo. E daí com o solo preservado é melhor, dá pra plantar mais coisas e a gente se alimenta (A-22).

O que sustenta o solo é a palha e os adubos (A-14).

$\mathrm{O}$ ato de sustentar, como define o dicionário Aurélio, trata o termo como "segurar por baixo; servir de escora a; impedir que caia; suportar, apoiar [...] Conservar, manter [...] Fornecer ou garantir o necessário para a sobrevivência de [...] Proteger, favorecer, auxiliar [...] suster-se, equilibrar-se [...]” (FERREIRA, 2009, p. 1902).

Segundo Boff (2015, p. 32), devemos pensar o ato de sustentar no seu sentido ativo, em que se enfatiza a ação feita de fora para "conservar, manter, proteger, nutrir, alimentar, fazer prosperar, substituir, viver" (grifo do autor). Trazendo para o dialeto ecológico, a sustentabilidade representa os procedimentos que tomamos para permitir que a Terra e seus 
Ensino, Saúde e Ambiente - V12 (3), pp. 162-180, Dez. 2019

biomas se mantenham sempre vivos, protegidos, alimentados de nutrientes a ponto de estarem sempre bem conservados e à altura dos riscos que possam advir.

Os demais estudantes, ou 53\% deles, apresentaram conceitos ligados à preservação, adubação, utilização de palhada para proteger e combater a erosão, como entendimento para a sustentabilidade dos solos.

Conforme seguem as respostas dos estudantes:

Fazer curva de nível para não dar erosão no solo. Deixar mais palhas. Botar adubo (A-23).

Que não pode só plantar, plantar e não botar nada de fertilizantes e outras coisas no solo (A-8).

Proteger o solo, deixar a palha e quando vem a chuva não leva a terra (A-7).

Eu acho que é quando tu cuida do solo e não quando tu destrói ele, quando tu tá preservando ele, quando tu tá cuidando ele, aí vai ser melhor (A-13).

Dessa forma, percebe-se que todas as repostas estão dentro das expectativas almejadas, pois todas tratam, de alguma forma, de proteção ao solo e prevenção de danos ao mesmo ao mencionar as práticas ecologicamente corretas de seu uso. É conveniente destacar que a utilização do termo "sustentar" remete à ética do cuidado, do pensamento e da preocupação para com todos: penso em mim, em minhas ações, mas também no que isso vai influenciar para o meu próximo, como um todo.

Para tanto, percebe-se que a percepção dos alunos, em ambos os procedimentos de coletas de dados, partem da visão própria dos mesmos, como é o caso dos questionários e respostas inicias, baseados em suas vivências e experiências de vida.

As respostas ou manifestações são, portanto, resultado das percepções, dos processos cognitivos, julgamentos e expectativas de cada indivíduo. Embora nem todas as manifestações psicológicas sejam evidentes, são constantes, e afetam nossa conduta, na maioria das vezes, inconscientemente. Assim, o estudo da percepção ambiental é de fundamental importância para que possamos compreender melhor as inter-relações entre o homem e o ambiente, suas expectativas, satisfações e insatisfações, julgamentos e condutas (FAGGIONATO, apud COSTA; MAROTI, 2013, p. 2380).

Após a aplicação da sequência didática contextualizada, observa-se que a percepção dos estudantes é ampliada, pois a troca de conhecimentos com os demais sujeitos, aliado à discussão entre os pares e prática contextualizada de ensino, favorece a construção de alguns conceitos e enriquece a percepção sobre a sustentabilidade dos solos.

Portanto, as percepções para a sustentabilidade, onde refletem as práticas conservacionista de solo, devem estar integradas ao todo, não separadas. Claro que quando 
estamos falando em preservação, estamos preocupados com a continuidade da espécie, porém, é necessário pensar de forma ampla, e na condição de que tudo faz parte do todo, e vice-versa.

Cabe destacar que muitas vezes, quando pensamos em preservação, pensamos na condição de atitudes independentes umas das outras. É de extrema importância que se quisermos um planeta com condições adequadas e saudáveis de vida às futuras gerações, devemos pensar no coletivo e de forma coletiva, em prol do bem comum.

Tanto nas escolas, como na sociedade em geral, as ações ambientais devem estar relacionais com as questões sociais e econômicas, para que haja um balanceamento e a sustentabilidade ocorra de forma coerente. Não que o pensamento preservacionista não funcione para a sustentabilidade. Pelo contrário, a sensibilização para a preservação é o primeiro passo para o entendimento maior da sustentabilidade como todo.

Assim, analisando o termo sustentabilidade, após compiladas percepções dos estudantes e congregadas com as concepções da pesquisadora, observou-se primeiramente que se deve compreender algumas questões para ousar pré-definir o conceito de sustentabilidade dos solos. O sistema que abrange os 3 pilares de desenvolvimento, segundo o famoso tripé de John Elkington, criado em 1990, o Triple Bottom Line (a linha das três pilastras) ou 3 Ps da Sustentabilidade (People, Planet, Profit, ou em português PPL Pessoas, Planeta e Lucro). Este modelo, segundo Boff, é o modelo-padrão de desenvolvimento sustentável como normalmente é pensado e buscado nas empresas e aparece nos discursos oficiais (BOFF, p. 43). Para ser sustentável o desenvolvimento deve ser economicamente viável, socialmente justo e ambientalmente correto, conforme aparece na Figura 1.

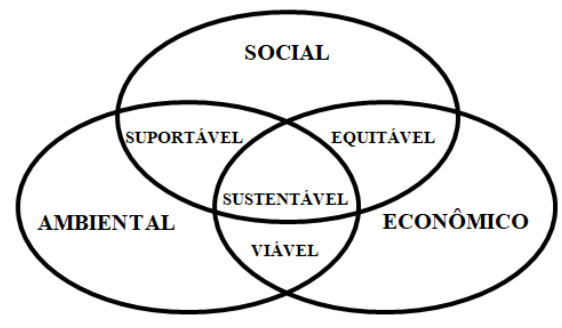

Figura 1 - Três Pilares da Sustentabilidade. Fonte: Adaptado de RANGEL, 2015.

Trazendo para os preceitos dos solos e sua utilização na agricultura, podemos organizá-los, segundo o Triple Bottom Line:

Economicamente viável - solo ser capaz de auto recuperar-se, utilizar metodologias alternativas para adubar o solo, bem como práticas que combatam a erosão e não deixem o 
Ensino, Saúde e Ambiente - V12 (3), pp. 162-180, Dez. 2019

material orgânico e sais minerais serem levados quando de chuvas torrenciais ou vento. Poderíamos compreender, em termos econômicos, em alternativas que não requerem muitos gastos ao produtor, ou que minimizem os custos de produção, aliando, é claro, a alternativas limpas e pouco invasivas de manejo de solo.

Socialmente justa - para com todos, todos terem direito à terra saudável e produtiva - possuir um solo fértil, com vistas à produção do alimento limpo e sadio às presentes e futuras gerações.

Ecologicamente correta - que as práticas de utilização do solo causem menos impacto possível, para que a natureza possa se auto recuperar sem interferir em nenhum ciclo dos seres, pois na verdade todos os seres são importantes para a preservação da espécie humana.

Sabe-se que a definição das três pilastras de desenvolvimento sustentável é criticada pela grande maioria dos pensadores do assunto. De acordo com Boff (2015), ao aceitar as três pilastras, deveria-se acrescentar algumas complementares, entre elas: gestão da mente sustentável, generosidade, cultura, neuroplasticidade do cérebro e o cuidado essencial.

Como gestão da mente sustentável: formulado pelo professor Evandro Vieira Ouriques, da Escola de Comunicação da Universidade Federal do Rio de Janeiro, tenta-se resgatar o valor da razão sensível pela qual o ser humano se sente parte da natureza, impõe-se um autocontrole para superar a compulsão pelo crescimento, pelo produtivismo e pelo consumismo (BOFF, 2015).

No que tange à generosidade, segundo Rogério Ruschel, criador desta pilastra, destaca que a mesma é indispensável para o desenvolvimento sustentável, uma vez que o ser humano "é um ser social que coloca os bens comuns acima dos particulares ou que põe os interesses dos outros no mesmo nível de seus próprios interesses” (BOFF, 2015, p. 49). Morin (2000, p. 47) descreve, neste mesmo sentido que "conhecer o humano é, antes de mais nada, situá-lo no universo, e não separá-lo dele”.

Quanto à cultura, quarto pilar da sustentabilidade, aceito na Rio+10, em Joanesburgo no ano de 2002, Boff (2015, p. 50) destaca que este pilar “encerra a coesão social, valores, processos de comunicação e diálogo e favorece o cultivo das dimensões tipicamente humanas como a arte, a religião, a criatividade, as ciências e outras tantas formas de expressão estética". 
A neuroplasticidade do cérebro, pilar ainda em construção mas que já constitui vasta investigação, e que pode oferecer boas possibilidades de desenvolvimento social que, justo e sustentável, repercute na mente que coevolui junto com o processo global de um mundo mais sustentável (BOFF, 2015).

O termo cuidado essencial, criado pelo próprio Leonardo Boff o descreve como essencial para a sustentabilidade "entendo o cuidado como substantivo, quer dizer, como um dado ontológico e uma constante para todos os organismos vivos” (BOFF, 2015, p. 51).

As definições de Boff complementam o pensamento de Morin (2000, p. 67), ao definir que "O mundo torna-se cada vez mais um todo. Cada parte do mundo faz, mais e mais, parte do mundo e o mundo, como um todo, está cada vez mais presente em cada uma de suas partes".

Deste modo todas as definições anteriormente apresentadas, que permeiam a sustentabilidade e que a tornam um conceito humanamente e ambientalmente mais sensível, encontram-se com o que pensam os estudantes e a pesquisadora que conduz este ensino, e são estes que deveriam estar presentes em todas as relações e práticas cotidianas.

Ao observar, assim, que há valores intrínsecos no sentido maior de sustentabilidade, pode-se fazer uma tentativa do que seria o tripé da sustentabilidade dos solos. Baseando-se em conceitos discutidos, caracterizar-se-ia da seguinte maneira, conforme mostra a Figura 2.

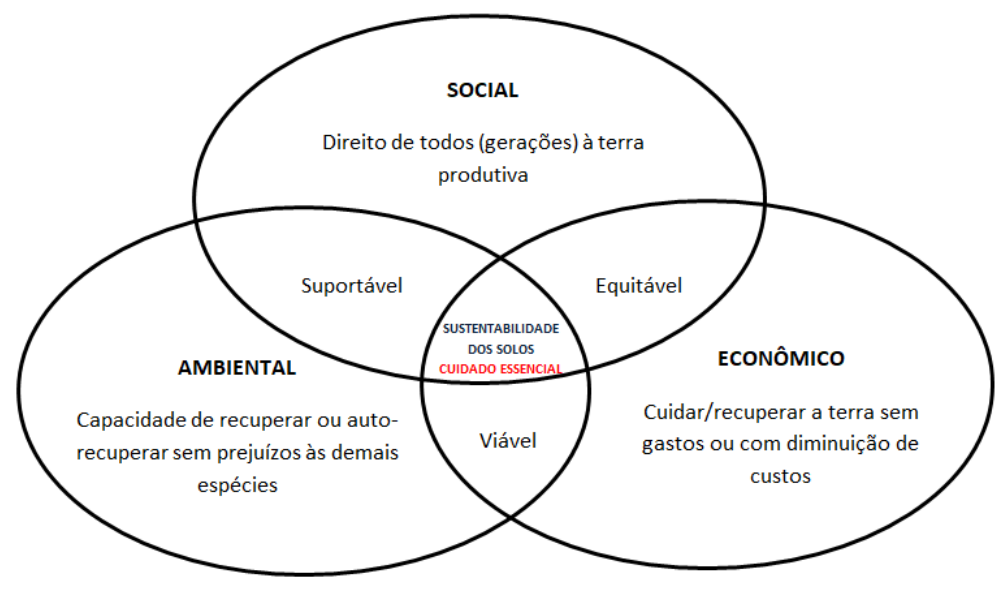

Figura 2 - Modelo de tripé proposto para a Sustentabilidade dos Solos.

Fonte: Autoria própria.

Para Guerra e Angelo-Menezes (1999), ao tratar o termo sustentabilidade dos solos, se contempla principalmente o ciclo dos nutrientes e seu retorno ao sistema produtivo, 
reforçando a ideia defendida da capacidade do solo se auto recuperar, com a diminuição de custos nas plantações, assegurando o direito de todos às terras férteis e produtivas.

Neste âmbito, o cuidado essencial, que está localizado entre as três pilastras, e que as une, refere-se não como uma virtude ou uma simples atitude de zelo e de preocupação com aquilo que nos sentimos envolvidos, mas fundamentalmente, configura um modo de ser, uma relação nova para com a realidade, a Terra, a natureza e outro ser humano, pois quem cuida não se coloca sobre o outro, dominando-o, mas junto dele, convivendo, dando-lhe conforto e paz. (BOFF, 2015)

Deve-se considerar que no intuito de colocar-se lado a lado, como peça fundamental para o desenvolvimento e mudança que se almeja ao Planeta Terra, que "o homem é homem e o mundo é histórico-cultural na medida em que, ambos inacabados, se encontram numa relação permanente, na qual o homem, transformando o mundo, sofre os efeitos de sua própria transformação" (FREIRE, 2015, p. 101).

\section{CONSIDERAÇÕES FINAIS}

Diante dos resultados propostos, e do ponto de vista de transformação do sujeito, os estudantes da pesquisa estão no caminho de um pensamento para a sustentabilidade, mesmo sem saber a definição do termo em si, mas considerando que há uma aproximação das percepções com as referências relacionadas no estudo. Cabe aqui destacar, que há de se construir um significado preciso para o termo "sustentabilidade dos solos", e com base nos diagnósticos, tentou-se oferecer um caminho a ser percorrido nesta pesquisa.

Devemos considerar que a aproximação dos estudantes com o meio é favorecida neste estudo, do pensar para a sustentabilidade, mas, é essencial que este pensamento esteja presente nas concepções dos professores, e que estes estejam aptos para atuarem de forma integradora e participativa. Também deve, o sistema como um todo, pensar de forma sustentável, permitindo que os conteúdos e metodologias de ensino estejam e sejam mais próximas ao cotidiano dos estudantes.

Considera-se dessa forma, também e não menos importante, a formação de docentes para pensar a sustentabilidade, onde os conteúdos sejam vislumbrados e trabalhados de forma sistêmica e transversal, e não isolados do contexto. Deve-se permitir que o educando faça parte do processo de aprendizagem, em que o papel do professor seja o de facilitador, e para que o mesmo tome consciência de que faz parte da mudança, e que ela é possível quando isso ocorre. 
Faz-se necessário, cada vez mais, que instiguemos os nossos estudantes a pensarem de forma sustentável, que os processos sejam pensados dessa forma, que o planejamento aconteça como um todo. É necessário que o processo em si seja sustentável para haver o entendimento. A contextualização também é aliada quanto à construção dos conceitos, principalmente no que tange a sustentabilidade.

A ética do cuidado, citada por Boff (2015), aliada aos demais pilares que sustentam o termo sustentabilidade devem estar integrados aos conteúdos e metodologias na escola, para que possamos auxiliar na sensibilização de cidadãos mais conscientes, a fim de deixar um ambiente equilibrado às presentes e futuras gerações, gozando do equilíbrio e do retorno que este compromisso traz.

Diante da preocupação, não somente para com o solo, mas com o meio ambiente como um todo, devemos tratar dos elementos essenciais à vida com carinho e cuidado, pois esta geração precisa do solo e também as próximas que virão, principalmente para a produção de alimentos e continuidade das espécies.

\section{REFERÊNCIAS}

AGENDA 21 GLOBAL E BRASILEIRA. Disponível em: http://www.mma.gov.br/port/se/agen21/ag21global/. Acesso em: 15 set. 2017.

BRASIL. Conselho Nacional de Educação. Câmara de Educação Básica. Resolução CNE/CEB n ${ }^{\circ} 1$, de 3 de abril de 2002. Institui Diretrizes Operacionais para a Educação Básica nas Escolas do Campo. Disponível em: http://pronacampo.mec.gov.br/images/pdf/mn_resolucao_\%201_de_3_de_abril_de_2002.pdf. Acesso em: 07 jul. 2017.

BOFF, L. Sustentabilidade: o que é - o que não é. 4. ed. Petrópolis, RJ: Vozes, 2015. COMISSÃO MUNDIAL SOBRE MEIO AMBIENTE E DESENVOLVIMENTO CMMDA. Nosso futuro comum. Rio de Janeiro: Fundação Getúlio Vargas, 1988.

COSTA, C. C.; MAROTI, P. S. Percepção ambiental de docentes em escola rural no estado de Sergipe. Revista Monografias Ambientais - Remoa/UFSM, v. 11, n. 11, p. 2379 - 2388, jan./abr. 2013.

ELTZ, F. L. F. et al. Manejo e conservação do solo. Uso, manejo e conservação do solo. Universidade Federal de Santa Maria: Centro de Ciências Rurais. Departamento de Solos. Santa Maria, 2007.

ESCOLA ESTADUAL DE ENSINO FUNDAMENTAL ANDREA PARISE. Projeto Político Pedagógico. Tuparendi, RS, 2010. 
Ensino, Saúde e Ambiente - V12 (3), pp. 162-180, Dez. 2019

FERREIRA, A. B. de H. Novo dicionário Aurélio da Língua Portuguesa. Coordenação Marina Baird Ferreira, Margarida dos Anjos. 4. ed. Curitiba: Editora Positivo, 2009.

FREIRE, P. Extensão ou comunicação? 17. ed. São Paulo: Paz e Terra, 2015.

FREIRE, P. Pedagogia da Autonomia: saberes necessários à prática educativa. São Paulo: Paz e Terra, 2011.

GIL, A. C. Como elaborar projetos de pesquisa. 4.ed. São Paulo: Atlas, 2002.

GLIESSMAN, S. R. Agroecologia: processos ecológicos em agricultura sustentável. Porto Alegre: Ed. Universidade/UFRGS, 2000.

GUERRA, G. A. D.; ANGELO-MENEZES, M. de N. Do conceito de fertilidade ao de sustentabilidade. Novos Cadernos NAEA, v. 2, n. 2, p. 139-157, dez. 1999.

MORAES, R. Uma tempestade de luz: a compreensão possibilitada pela análise textual discursiva. Ciência \& Educação, v. 9, n. 2, p. 191-211, 2003.

MORAES, R.; GALIAZZI, M. do C. Análise Textual Discursiva. 3. ed. Ijuí: Ed. Unijuí, 2016.

MORIN, E. Os sete saberes necessários à educação do futuro. Tradução: Catarina E.F. da Silva e Jeanne Sawaya. Revisão técnica de Edgard de Assis Carvalho. 2. ed. São Paulo:

Cortez. Brasília, DF: UNESCO, 2000.

PIRES, A. H. B.; BAPTISTA, N. de Q. Temas específicos essenciais a um currículo contextualizado no semiárido brasileiro. In: DUARTE, A. P. M.; CARNEIRO, V. M. O. (Org.). Contribuições para construção de um currículo contextualizado para o semiárido. Feira de Santana: MOC/Curviana, 2013. p.162-176.

PRIMAVESI, A. Pergunte ao solo e às raízes: uma análise do solo tropical e mais de 70 casos resolvidos pela agroecologia. 1. ed. São Paulo: Nobel, 2014.

RANGEL, J. Arquitetura ecológica x Arquitetura sustentável - SustentArqui. Rio de Janeiro, 2015. Disponível em http://sustentarqui.com.br/dicas/arquitetura-ecologica-X-arquiteturasustentavel/. Acesso em: 10 out. 2017.

THIOLLENT, M. Metodologia da Pesquisa-Ação. São Paulo: Cortez, 1985.

\section{SOBRE OS AUTORES}

\section{AUTOR 1.}

A autora Patrícia Daiane Loebens Diel Wiethölter é professora da educação básica e atualmente trabalha como extensionista rural social na EMATER/RS - ASCAR. O estudo apresentado faz parte de uma pesquisa sobre metodologia contextualizada acerca da sustentabilidade dos solos em uma escola do campo, abrangendo os Objetivos do Desenvolvimento Sustentável.

\section{AUTOR 2.}


A autora Maria Rosa Chitolina trabalha na área de Educação em Ciências há aproximadamente 10 anos. Sua linha de pesquisa é em ensino e aprendizagem sendo que nos últimos anos tem trabalhado assuntos relacionados ao desenvolvimento sustentável. Neste trabalho especificamente foram trabalhando os ODS (Objetivos do Desenvolvimento Sustentável) de números 4 e 15, focando nos solos e sua conservação. 